\title{
Comparative efficacy of modified FOLFIRINOX, gemcitabine plus capecitabine and gemcitabine plus nab-paclitaxel as adjuvant treatment for resected pancreatic cancer: a Bayesian network meta-analysis
}

\author{
Victor Hugo Fonseca de Jesus and Rachel P Riechelmann \\ Medical Oncology Department, A.C. Camargo Cancer Center, Rua Prof. Antônio Prudente 211, São Paulo SP 01509-010, Brazil
}

\begin{abstract}
Background: There are no head-to-head comparisons evaluating the efficacy of the main polychemotherapy regimens used for patients with pancreatic cancer in the adjuvant setting. We aimed to describe the relative efficacy of modified FOLFIRINOX (mFOLFIRINOX), gemcitabine plus capecitabine (GEM-CAP) and gemcitabine plus nab-paclitaxel (GEM-NAB) in this setting using a Bayesian network approach.
\end{abstract}

Methods: We collected data from the ESPAC-4, PRODIGE 24 and APACT trials. Diseasefree survival (DFS), according to the investigators, and overall survival (OS) for the three polychemotherapy regimens were compared using gemcitabine as the reference arm. We ran Markov chain Monte Carlo simulations with a fixed-effect model to generate the posterior distribution of the hazard ratios (HRs) using non-informative priors. Relative efficacy was measured by HRs, surface under cumulative ranking and rankograms.

Results: mFOLFIRINOX was the chemotherapy regimen most likely to be the most effective in the adjuvant setting (98.9\% and $89.6 \%$ probability for DFS and OS, respectively). GEM-NAB marginally improved DFS ( $\mathrm{HR}=0.97,95 \%$ credible interval $(95 \% \mathrm{Crl})=0.77-$ 1.21) and $\mathrm{OS}(\mathrm{HR}=0.98,95 \% \mathrm{Crl}=0.76-1.25)$ when compared to GEM-CAP. However, GEM-NAB had the highest chances of being the second most active chemotherapy regimen (61.4\% and 52.5\% probability for DFS and OS, respectively), whereas GEM-CAP was less likely to represent the second most active regimen $(37.7 \%$ and $40.1 \%$ probability for DFS and OS, respectively).

Conclusion: For patients eligible and fit enough to undergo adjuvant treatment with mFOLFIRINOX, this constitutes the treatment of choice. For those with contraindications

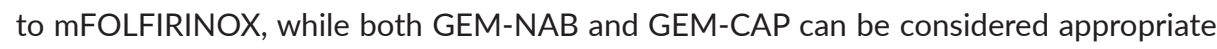
alternatives, GEM-NAB is likely the most effective regimen.

Keywords: FOLFIRINOX, gemcitabine, capecitabine, nab-paclitaxel, adjuvant, pancreatic, cancer
Correspondence to: Victor Hugo Fonseca de Jesus Email: victor.jesus@accamargo.org.br

ecancer 2021, 15:1276

https://doi.org/10.3332/ecancer.2021.1276

Published: $16 / 08 / 2021$

Received: 23/10/2020

Publication costs for this article were supported by ecancer (UK Charity number 1176307).

Copyright: ( $)$ the authors; licensee ecancermedicalscience. This is an Open Access article distributed under the terms of the Creative Commons Attribution License (http:// creativecommons.org/licenses/by/4.0), which permits unrestricted use, distribution, and reproduction in any medium, provided the original work is properly cited. 


\section{Background}

Pancreatic cancer currently stands as the 14th most common type of cancer worldwide, with 458,918 estimated cases in 2018 [1]. In the same year, it represented the seventh most common cause of cancer-related mortality, with 432,242 estimated deaths. Furthermore, data from developed [2,3] and developing [4] countries suggest that the burden of pancreatic neoplasms in cancer epidemiology is expected to grow significantly in the decade to come. This high lethality rate is partially related to the disease stage at diagnosis. Only $15 \%-20 \%$ of the patients are candidates for curative-intent surgery [5]. Moreover, for those submitted to surgery, survival outcomes are dismal when this treatment modality is used in isolation [6].

In this sense, the ESPAC-1 [7] and the CONKO-001 [8, 9] have established the role of 5-Fluorouracil and gemcitabine in the treatment of localised pancreatic cancer, respectively. Subsequently, these two drugs were compared in the ESPAC-3 trial [10]. The authors demonstrated that while there were no differences in survival, gemcitabine was associated with lower rates of treatment-related serious adverse events (7.5\% versus $14.0 \%)$. As a result, gemcitabine became the standard chemotherapy regimen in this scenario.

With the rise of polychemotherapy regimens such as FOLFIRINOX and gemcitabine-based combinations in the metastatic setting [11-13], randomised trials were designed to assess whether patients could benefit from treatment intensification in the setting of less advanced disease. While two randomised trials showed no benefit of adding erlotinib to gemcitabine [14, 15], three randomised trials demonstrated improved overall survival (OS) with combination chemotherapy: the ESPAC-4 (gemcitabine plus capecitabine (GEM-CAP)) [16], the PRODIGE 24 (modified FOLFIRINOX) [17] and the APACT (gemcitabine plus nab-paclitaxel (GEM-NAB)) trials [18].

At this moment, there are no randomised trials directly comparing these three chemotherapy regimens and such comparisons are unlikely to be ever pursued in a controlled setting. Thus, we analysed the results of these trials using a Bayesian network meta-analysis framework. This methodology allows us to infer the probable gains (e.g., in OS) of an intervention over another when formal direct comparisons of therapies through randomised trials are not available. An advantage of this approach is that one can generate probabilistic results that can support the decision-making process [19]. Our aim was to establish the relative efficacy and to compare the toxicity profile of each of these chemotherapy regimens using single-agent gemcitabine as the reference treatment.

\section{Methods}

\section{Data extraction and collection}

Data regarding the inclusion and exclusion criteria, the characteristics of the studies' populations and the toxicity profile were extracted from the original publications for the ESPAC-4 [16] and PRODIGE 24 [17] trials and from the 2019 American Society of Medical Oncology Annual Meeting presentation for the APACT trial [18]. Additionally, updated survival data were extracted from recent presentations for the ESPAC-4 [20] and the APACT trials [21].

\section{Treatment schedules}

In the experimental arm of the ESPAC-4 trial, patients received capecitabine $1,660 \mathrm{mg} / \mathrm{m}^{2}$ for 21 days followed by a 7 days' rest plus gemcitabine $1,000 \mathrm{mg} / \mathrm{m}^{2}$ once a week for three every 4 weeks. In the PRODIGE 24 study, patients assigned to combination chemotherapy received 5-Fluorouracil 2,400 mg/m² (46-hour continuous infusion), irinotecan $150 \mathrm{mg} / \mathrm{m}^{2}$, oxaliplatin $85 \mathrm{mg} / \mathrm{m}^{2}$ and folinic acid $400 \mathrm{mg} / \mathrm{m}^{2}$ once every 2 weeks. In the experimental arm of the APACT trial, patients received nab-paclitaxel $125 \mathrm{mg} / \mathrm{m}^{2}$ and gemcitabine $1,000 \mathrm{mg} / \mathrm{m}^{2}$ once a week for three every 4 weeks. In the control arms of the trials, patients received gemcitabine $1,000 \mathrm{mg} / \mathrm{m}^{2}$ weekly for three every 4 weeks. For all treatments, the planned adjuvant treatment duration was 24 weeks. 


\section{Outcomes}

The primary outcome was OS in the intention-to-treat population. In all three trials, it was defined as the time from randomisation to death. It was the primary outcome of the ESPAC-4 and the PRODIGE 24 trials. As a secondary outcome, we analysed investigator-assessed disease free-survival (DFS) (relapse-free survival in the ESPAC-4) in the intention-to-treat population. In all three trials, it was defined as the time from randomisation to death or disease progression. It was a secondary outcome of the ESPAC-4 and PRODIGE 24 trials, and it was a prespecified sensitivity analysis of the primary outcome of the APACT study (independently assessed DFS). Since comparable depiction of either any severe or any grade 3-4 adverse events across the three studies was not available, we did not perform a Bayesian network meta-analysis on toxicity. Therefore, data on toxicity are summarised using only descriptive statistics.

\section{Statistical analysis}

Before data analysis, we assessed the transitivity assumption by inspecting the characteristics of the populations and the inclusion and exclusion criteria of the studies [22]. Data on time-to-event outcomes (DFS and OS) were extracted using hazard ratios (HRs) and their 95\% confidence intervals $(\mathrm{Cls})(95 \% \mathrm{Cl})$. Before data manipulation, we used the approach described by Parmar et al [23] to convert these measures into log(HR) and selog(HR), respectively. In the Supplementary Material, we have provided formulas and model specifications in accordance with Hu et al [24]. Given the limited number of studies and the indirect nature of all the comparisons between polychemotherapy regimens, there would be no information on between-trial heterogeneity for pairwise comparisons. Thus, we employed a pragmatic approach in which we fit a fixed-effect model to the data [25]. We used a Markov chain Monte Carlo (MCMC) method using Gibbs' sampling algorithm to perform network meta-analyses (codes are available in the Supplementary Material). Briefly, using non-informative priors (mean equal to 0 and variance equal to 1,000) and after a burn-in phase of 40,000 iterations using three chains, we drew 120,000 samples from the posterior distribution (40,000 additional iterations for each chain without thinning). We chose non-informative priors so that results of the analyses would be driven solely by the data from the studies. Parameter convergence was checked by inspection of the Brooks-Gelman-Rubin plots [26]. Gemcitabine was used as the reference comparator (common to all trials). Pairwise comparisons were summarised using HRs and 95\% credible intervals (95\% Crls). By definition, the true value of the parameter (HR in this case) has a 95\% probability of belonging to such an interval [27]. To portray effectiveness, we ranked treatments according to surface under cumulative ranking (SUCRA) and plotted treatment ranks against their probabilities using rankograms [28]. These probabilities were calculated as the ratio between the number of cycles of the MCMC in which a specific treatment had a log HR (effect size) more or less than the ones of other treatments and the total number of cycles of the MCMC. We compared the distribution of categorical variables across studies with Fisher's exact test or chi-square test. Bayesian analyses were conducted using the software WinBUGS version 1.4.3 (MRC Biostatistics Unit, Cambridge, UK). The comparisons of categorical variables across studies and the graphics were carried out using the software R version 3.6.0.

\section{Results}

The network map is shown in Figure 1. Overall, the studies presented similar inclusion and exclusion criteria - Supplementary Table 1. Patients included in these trials should be 18 years old or above, have the pathological diagnosis of ductal adenocarcinoma and have been submitted to microscopically complete (RO) or incomplete (R1) resection. Also, patients should present an Eastern Cooperative Oncology Group (ECOG) performance status (PS) 0 or 1 at randomisation. However, slight differences among the studies' protocols were noted. Patients aged 80 years old or above were not included in the PRODIGE 24 study. Also, the ESPAC-4 study allowed for the enrolment of patients with ECOG PS 2. Importantly, both ESPAC-4 and APACT mandated a CT scan at least 3 months before patient registration. Lastly, the PRODIGE 24 and the APACT studies excluded patients with post-operative Carbohydrate antigen 19-9 (CA 19-9) levels above 180 and 100 UI/mL, respectively.

Table 1 describes the characteristics of the studies' populations. Despite similar inclusion and exclusion criteria, we observed differences in the distribution of patients' characteristics across trials. We noted significant differences in the rate of microscopically involved resection margins (R1 resection), with a high rate seen particularly in the ESPAC-4 trial. Moreover, patients in the ESPAC-4 trial more often presented with stage III disease. Despite these differences, we considered that, based on the similar inclusion and exclusion criteria among the trials, the populations were homogenous enough for the transitivity assumption to be valid. The assessment of the Brooks-Gelman-Rubin plots suggested model convergence for all comparisons of HRs. 


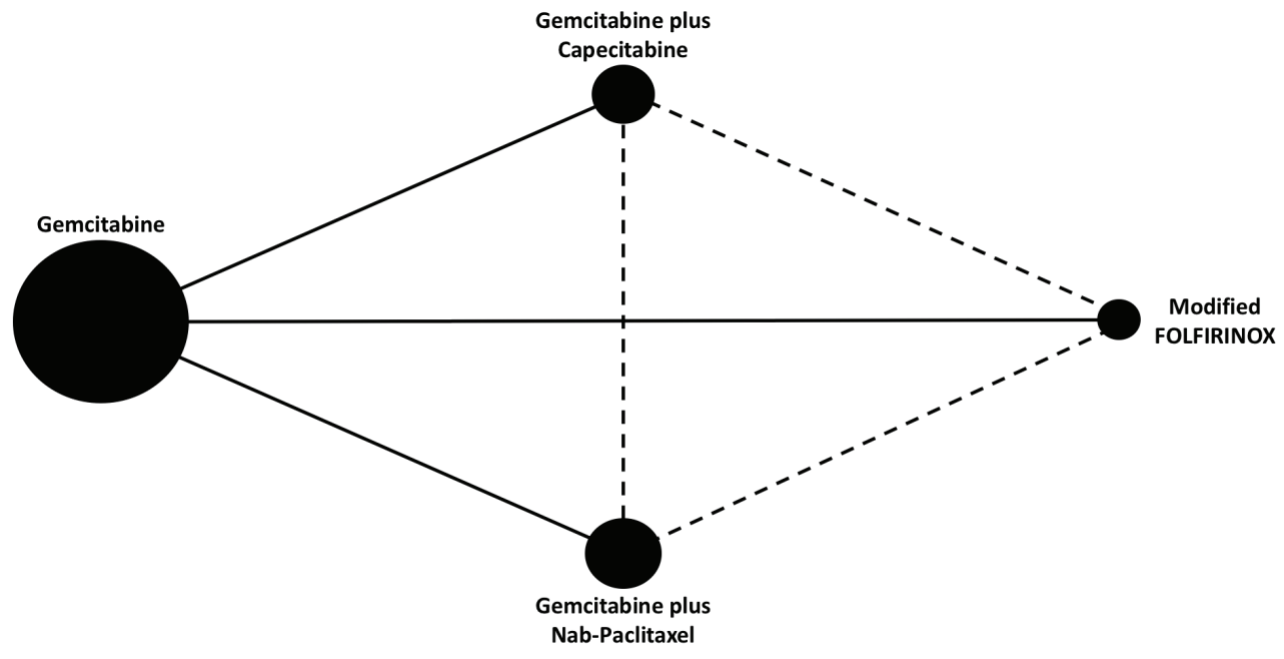

Figure 1. Network map. Each node represents a chemotherapy regimen. The node size reflects the total number of patients treated with a specific chemotherapy regimen across studies. Solid lines represent direct comparisons. Dashed lines represent indirect comparisons.

Table 1. Characteristics of the studies' populations.

\begin{tabular}{|c|c|c|c|c|c|c|c|}
\hline & \multicolumn{2}{|c|}{ ESPAC-4 } & \multicolumn{2}{|c|}{ PRODIGE 24} & \multicolumn{2}{|c|}{ APACT } & \multirow{3}{*}{$p$ value } \\
\hline & Gemcitabine & GEM-CAP & Gemcitabine & $\begin{array}{c}\text { Modified } \\
\text { FOLFIRINOX }\end{array}$ & Gemcitabine & GEM-NAB & \\
\hline & $N=366(\%)$ & $N=364(\%)$ & $N=246(\%)$ & $N=247(\%)$ & $N=434(\%)$ & $N=432(\%)$ & \\
\hline $\begin{array}{l}\text { Sex } \\
\text { Male } \\
\text { Female }\end{array}$ & $\begin{array}{l}212(57.9) \\
154(42.1)\end{array}$ & $\begin{array}{l}202(55.5) \\
162(44.5)\end{array}$ & $\begin{array}{l}135(54.9) \\
111(45.1)\end{array}$ & $\begin{array}{l}142(57.5) \\
105(42.5)\end{array}$ & $\begin{array}{l}253(58.3) \\
181(41.7)\end{array}$ & $\begin{array}{l}228(52.8) \\
204(47.2)\end{array}$ & $0.894^{b}$ \\
\hline $\begin{array}{l}\text { Age (years) } \\
\text { Median } \\
\text { Range }\end{array}$ & $\begin{array}{c}65 \\
37-80 \\
\end{array}$ & $\begin{array}{c}65 \\
39-81 \\
\end{array}$ & $\begin{array}{c}64 \\
(30-81) \\
\end{array}$ & $\begin{array}{c}63 \\
(30-79) \\
\end{array}$ & $\begin{array}{c}64 \\
38-86 \\
\end{array}$ & $\begin{array}{c}64 \\
34-83 \\
\end{array}$ & - \\
\hline $\begin{array}{l}\text { ECOG PSa } \\
0 \\
1 \\
2 \\
\text { Unknown }\end{array}$ & $\begin{array}{c}158(43.2) \\
199(54.4) \\
9(2.4) \\
0(0.0) \\
\end{array}$ & $\begin{array}{c}150(41.2) \\
202(55.5) \\
12(3.3) \\
0(0.0)\end{array}$ & $\begin{array}{c}127(51.6) \\
115(46.7) \\
0(0) \\
4(1.6) \\
\end{array}$ & $\begin{array}{c}122(49.4) \\
123(49.8) \\
0(0) \\
2(<1) \\
\end{array}$ & $\begin{array}{c}268(61.8) \\
166(38.2) \\
0(0.0) \\
0(0.0)\end{array}$ & $\begin{array}{c}252(58.3) \\
180(41.7) \\
0(0.0) \\
0(0.0) \\
\end{array}$ & $<0.001^{\text {b }}$ \\
\hline $\begin{array}{l}\text { Preoperative CA 19-9 (UI/mL) } \\
\text { Median } \\
\text { Range }\end{array}$ & $\begin{array}{c}142.5 \\
0.9-10761\end{array}$ & $\begin{array}{c}154.5 \\
0.8-76549\end{array}$ & - & - & $\begin{array}{l}- \\
-\end{array}$ & - & - \\
\hline $\begin{array}{l}\text { Postoperative CA 19-9 (UI/mL) } \\
\text { Median } \\
\text { Range }\end{array}$ & $\begin{array}{c}20.5 \\
0.1-2448.3\end{array}$ & $\begin{array}{c}17.6 \\
0.6-8112\end{array}$ & - & - & $\begin{array}{c}12.9 \\
-\end{array}$ & $\begin{array}{c}14.31 \\
-\end{array}$ & - \\
\hline $\begin{array}{l}\text { Resection margin } \\
\text { R0 resection } \\
\text { R1 resection }\end{array}$ & $\begin{array}{l}147(40.2) \\
219(59.8)\end{array}$ & $\begin{array}{l}143(39.3) \\
221(60.7)\end{array}$ & $\begin{array}{l}134(54.5) \\
112(45.5)\end{array}$ & $\begin{array}{c}148(59.9) \\
99(40.1)\end{array}$ & $\begin{array}{l}334(77.0) \\
100(23.0)\end{array}$ & $\begin{array}{l}327(75.7) \\
105(24.3)\end{array}$ & $<0.001^{\text {b }}$ \\
\hline
\end{tabular}


Table 1. Characteristics of the studies' populations. (Continued)

\begin{tabular}{|c|c|c|c|c|c|c|c|}
\hline $\begin{array}{l}\text { Tumour grade } \\
\text { Well differentiated } \\
\text { Moderately } \\
\text { differentiated } \\
\text { Poorly differentiated or } \\
\text { undifferentiated } \\
\text { Unknown }\end{array}$ & $\begin{array}{c}30(8.2) \\
192(52.5) \\
142(38.8) \\
2(0.5)\end{array}$ & $\begin{array}{c}32(8.8) \\
175(48.1) \\
149(40.9) \\
8(2.2) \\
\end{array}$ & $\begin{array}{l}79(32.1) \\
125(50.8) \\
29(11.8) \\
13(5.3) \\
\end{array}$ & $\begin{array}{c}70(28.3) \\
124(50.2) \\
35(14.2) \\
18(7.3)\end{array}$ & $\begin{array}{c}55(12.7) \\
241(55.5) \\
117(27.0) \\
21(4.8) \\
\end{array}$ & $\begin{array}{c}49(11.3) \\
264(61.1) \\
102(23.6) \\
17(3.9)\end{array}$ & $<0.001^{c}$ \\
\hline $\begin{array}{l}\text { Lymph nodes } \\
\text { Negative } \\
\text { Positive }\end{array}$ & $\begin{array}{c}67(18.3) \\
299(81.7)\end{array}$ & $\begin{array}{c}76(20.9) \\
288(79.1)\end{array}$ & $\begin{array}{c}68(27.6) \\
178(72.4)\end{array}$ & $\begin{array}{c}59(23.9) \\
188(76.1)\end{array}$ & $\begin{array}{l}122(28.1) \\
312(71.9)\end{array}$ & $\begin{array}{l}121(28.0) \\
311(72.0)\end{array}$ & $<0.001^{b}$ \\
\hline $\begin{array}{l}\text { Maximum tumour size }(\mathrm{mm}) \\
\text { Median } \\
\text { Range }\end{array}$ & $\begin{array}{c}30 \\
0-110\end{array}$ & $\begin{array}{c}30 \\
6-105\end{array}$ & $\begin{array}{c}30 \\
6-120\end{array}$ & $\begin{array}{c}30 \\
8-90\end{array}$ & - & - & \\
\hline $\begin{array}{l}\text { Tumour stage } \\
\text { (AJCC 7th Edition) } \\
\text { I } \\
\text { II } \\
\text { III } \\
\text { IV }\end{array}$ & $\begin{array}{c}7(1.9) \\
29(7.9) \\
325(88.8) \\
5(1.3)\end{array}$ & $\begin{array}{c}15(4.1) \\
20(5.5) \\
326(89.6) \\
3(0.8)\end{array}$ & $\begin{array}{c}14(5.7) \\
226(91.9) \\
1(0.4) \\
5(2.0)\end{array}$ & $\begin{array}{c}12(4.9) \\
226(91.5) \\
1(0.4) \\
8(3.2)\end{array}$ & $\begin{array}{l}- \\
- \\
-\end{array}$ & $\begin{array}{l}- \\
- \\
-\end{array}$ & $<0.001^{b}$ \\
\hline $\begin{array}{l}\text { Surgery } \\
\text { Whipple resection } \\
\text { Total pancreatectomy } \\
\text { Pylorus-preserving } \\
\text { resection } \\
\text { Distal pancreatectomy }\end{array}$ & $\begin{array}{c}188(51.4) \\
27(7.4) \\
122(33.3) \\
29(7.9)\end{array}$ & $\begin{array}{c}182(50.0) \\
22(6.0) \\
129(35.4) \\
31(8.5)\end{array}$ & $\begin{array}{c}190(77.2) \\
- \\
- \\
-\end{array}$ & $\begin{array}{c}202 \text { (81.8) } \\
- \\
- \\
\\
-\end{array}$ & $\begin{array}{l}- \\
- \\
- \\
-\end{array}$ & $\begin{array}{l}- \\
- \\
- \\
-\end{array}$ & - \\
\hline $\begin{array}{l}\text { Venous resection } \\
\text { No } \\
\text { Yes } \\
\text { Unknown }\end{array}$ & $\begin{array}{c}298(81.4) \\
63(17.2) \\
5(1.4)\end{array}$ & $\begin{array}{c}323(88.7) \\
39(10.7) \\
2(0.5)\end{array}$ & $\begin{array}{c}176(71.5) \\
69(28.0) \\
1(<1)\end{array}$ & $\begin{array}{c}192(77.7) \\
53(21.5) \\
2(<1)\end{array}$ & $\begin{array}{l}- \\
- \\
-\end{array}$ & $\begin{array}{l}- \\
-\end{array}$ & $<0.001^{b}$ \\
\hline $\begin{array}{l}\text { Lymphovascular invasion } \\
\text { No } \\
\text { Yes } \\
\text { Unknown }\end{array}$ & $\begin{array}{l}- \\
- \\
-\end{array}$ & $\begin{array}{l}- \\
- \\
-\end{array}$ & $\begin{array}{c}79(32.1) \\
135(54.9) \\
32(13.0) \\
\end{array}$ & $\begin{array}{l}55(22.3) \\
154(62.3) \\
38(15.4)\end{array}$ & $\begin{array}{l}- \\
- \\
-\end{array}$ & $\begin{array}{l}- \\
- \\
-\end{array}$ & - \\
\hline $\begin{array}{l}\text { Perineural invasion } \\
\text { No } \\
\text { Yes } \\
\text { Unknown }\end{array}$ & $\begin{array}{l}- \\
- \\
-\end{array}$ & $\begin{array}{l}- \\
- \\
-\end{array}$ & $\begin{array}{c}24(9.8) \\
207(84.1) \\
15(6.1)\end{array}$ & $\begin{array}{c}16(6.5) \\
205(83.0) \\
26(10.5)\end{array}$ & $\begin{array}{l}- \\
- \\
-\end{array}$ & $\begin{array}{l}- \\
- \\
-\end{array}$ & - \\
\hline
\end{tabular}

${ }^{a}$ ECOG PS: Eastern Cooperative Oncology Group (ECOG) performance status

'Based on Fisher's exact test; only for categorical variables

'Based on chi-square test; only for categorical variables

\section{Disease-free survival}

The median duration of follow-up in the three studies ranged from 33.6 to 53.3 months. Table 2 describes the survival outcomes of the trials. No significant difference in DFS according to the investigators was observed in ESPAC-4 $(p=0.069)$. Conversely, patients treated with combination chemotherapy experienced improved investigator-assessed DFS in both PRODIGE 24 and APACT. The relative efficacy in terms of 
DFS of each chemotherapy regimen is shown in Table 3. According to the rankogram, modified FOLFIRINOX had a 98.9\% probability of being the most active chemotherapy among the four regimens in the adjuvant setting (Figure 2). The analysis of SUCRA for DFS also described modified FOLFIRINOX as the single most active chemotherapy agent (Table 4). Additionally, GEM-NAB (61.4\% probability) was more likely than GEM-CAP (37.7\% probability) to be the second best chemotherapy regimen.

\section{Overall survival}

In all three trials, patients treated with combination chemotherapy experienced longer OS. The relative efficacy in terms of OS of each chemotherapy regimen is shown in Table 3. According to the rankogram, modified FOLFIRINOX had 89.6\% probability of being the most active chemotherapy among the four regimens in the adjuvant setting (Figure 2). The analysis of SUCRA for OS also described modified FOLFIRINOX as the single most active chemotherapy agent (Table 4). Additionally, GEM-NAB (52.5\% probability) was more likely than GEM-CAP (40.1\%) to be the second best chemotherapy regimen.

\section{Outcomes of patients treated with single-agent gemcitabine across trials}

There were significant differences in OS across trials for patients undergoing adjuvant treatment with single-agent gemcitabine (Table 2). Patients who were treated in the gemcitabine arm in the ESPAC-4 trial experienced numerically worse OS (median OS: 26.0 months; $95 \% \mathrm{Cl}$ = 22.7-28.4) when compared to those treated with the same regimen in the PRODIGE 24 (median OS: 35.0 months; 95\% $\mathrm{Cl}=28.7-43.9$ ) and APACT (median OS: 37.7 months) trials. However, there were no differences in the relapse-free survival for patients treated with singleagent gemcitabine across the three trials.

Table 2. Survival outcomes according to the treatments across studies.

\begin{tabular}{|c|c|c|c|c|c|c|}
\hline & \multicolumn{2}{|c|}{ ESPAC-4 } & \multicolumn{2}{|c|}{ PRODIGE 24} & \multicolumn{2}{|c|}{ APACT } \\
\hline & Gemcitabine & GEM-CAP & Gemcitabine & $\begin{array}{c}\text { Modified } \\
\text { FOLFIRINOX }\end{array}$ & Gemcitabine & GEM-NAB \\
\hline & $N=366$ & $N=364$ & $N=246$ & $N=247$ & $N=434$ & $N=432$ \\
\hline $\begin{array}{l}\text { Median follow-up - months } \\
(95 \% \mathrm{Cl})\end{array}$ & \multicolumn{2}{|c|}{$\begin{array}{c}43.2^{\mathrm{a}} \\
(39.7-45.5)\end{array}$} & \multicolumn{2}{|c|}{$\begin{array}{c}33.6 \\
(30.3-36.0)\end{array}$} & $\begin{array}{c}53.0 \\
-\end{array}$ & $\begin{array}{c}53.3 \\
-\end{array}$ \\
\hline \multicolumn{7}{|l|}{ DFS } \\
\hline $\begin{array}{l}\text { Median DFS - months } \\
(95 \% \mathrm{Cl})\end{array}$ & $\begin{array}{c}13.4 \\
(11.7-15.5)\end{array}$ & $\begin{array}{c}14.2 \\
(12.2-16.9)\end{array}$ & $\begin{array}{c}12.8 \\
(11.7-15.2)\end{array}$ & $\begin{array}{c}21.6 \\
(17.7-27.6)\end{array}$ & 13.7 & 16.6 \\
\hline $\begin{array}{l}\mathrm{HR} \\
(95 \% \mathrm{Cl})\end{array}$ & 1.0 & $\begin{array}{c}0.85 \\
(0.73-1.00)\end{array}$ & 1.0 & $\begin{array}{c}0.58 \\
(0.46-0.73)\end{array}$ & 1.0 & $\begin{array}{c}0.82 \\
(0.69-0.97)\end{array}$ \\
\hline \multicolumn{7}{|l|}{ OS } \\
\hline $\begin{array}{l}\text { Median OS - months } \\
(95 \% \mathrm{Cl})\end{array}$ & $\begin{array}{c}26.0 \\
(22.7-28.4)\end{array}$ & $\begin{array}{c}27.7 \\
(23.3-31.2)\end{array}$ & $\begin{array}{c}35.0 \\
(28.7-43.9)\end{array}$ & $\begin{array}{c}54.4 \\
(41.8-N A)\end{array}$ & $\begin{array}{c}37.7 \\
-\end{array}$ & $\begin{array}{c}41.8 \\
-\end{array}$ \\
\hline $\begin{array}{l}\mathrm{HR} \\
(95 \% \mathrm{Cl})\end{array}$ & 1.0 & $\begin{array}{c}0.84 \\
(0.70-0.99)\end{array}$ & 1.0 & $\begin{array}{c}0.64 \\
(0.48-0.86)\end{array}$ & 1.0 & $\begin{array}{c}0.82 \\
(0.69-0.97)\end{array}$ \\
\hline
\end{tabular}

aBased on original publication (not on updated analysis). For the ESPAC-4, administrative censoring occurred at 5 years of follow-up

$\mathrm{Cl}$, Confidence interval; NA, not reached 
Table 3. HRs and $95 \%$ Crls for DFS and OS.

\begin{tabular}{|c|c|c|c|c|}
\hline \multicolumn{5}{|c|}{ DFS } \\
\hline & Gemcitabine & GEM-CAP & GEM-NAB & $\begin{array}{c}\text { Modified } \\
\text { FOLFIRINOX }\end{array}$ \\
\hline \multicolumn{5}{|l|}{ Gemcitabine } \\
\hline GEM-CAP & $\begin{array}{c}0.85 \\
(0.73-0.99)\end{array}$ & & & \\
\hline GEM-NAB & $\begin{array}{c}0.82 \\
(0.70-0.97)\end{array}$ & $\begin{array}{c}0.97 \\
(0.77-1.21)\end{array}$ & & \\
\hline $\begin{array}{l}\text { Modified } \\
\text { FOLFIRINOX }\end{array}$ & $\begin{array}{c}0.58 \\
(0.46-0.73)\end{array}$ & $\begin{array}{c}0.69 \\
(0.52-0.90)\end{array}$ & $\begin{array}{c}0.72 \\
(0.53-0.94)\end{array}$ & \\
\hline \multicolumn{5}{|c|}{ OS } \\
\hline & Gemcitabine & GEM-CAP & GEM-NAB & $\begin{array}{c}\text { Modified } \\
\text { FOLFIRINOX }\end{array}$ \\
\hline \multicolumn{5}{|l|}{ Gemcitabine } \\
\hline GEM-CAP & $\begin{array}{c}0.84 \\
(0.71-1.00)\end{array}$ & & & \\
\hline GEM-NAB & $\begin{array}{c}0.82 \\
(0.69-0.97)\end{array}$ & $\begin{array}{c}0.98 \\
(0.76-1.25)\end{array}$ & & \\
\hline $\begin{array}{l}\text { Modified } \\
\text { FOLFIRINOX }\end{array}$ & $\begin{array}{c}0.65 \\
(0.48-0.86)\end{array}$ & $\begin{array}{c}0.77 \\
(0.54-1.07)\end{array}$ & $\begin{array}{c}0.79 \\
(0.56-1.10)\end{array}$ & \\
\hline
\end{tabular}

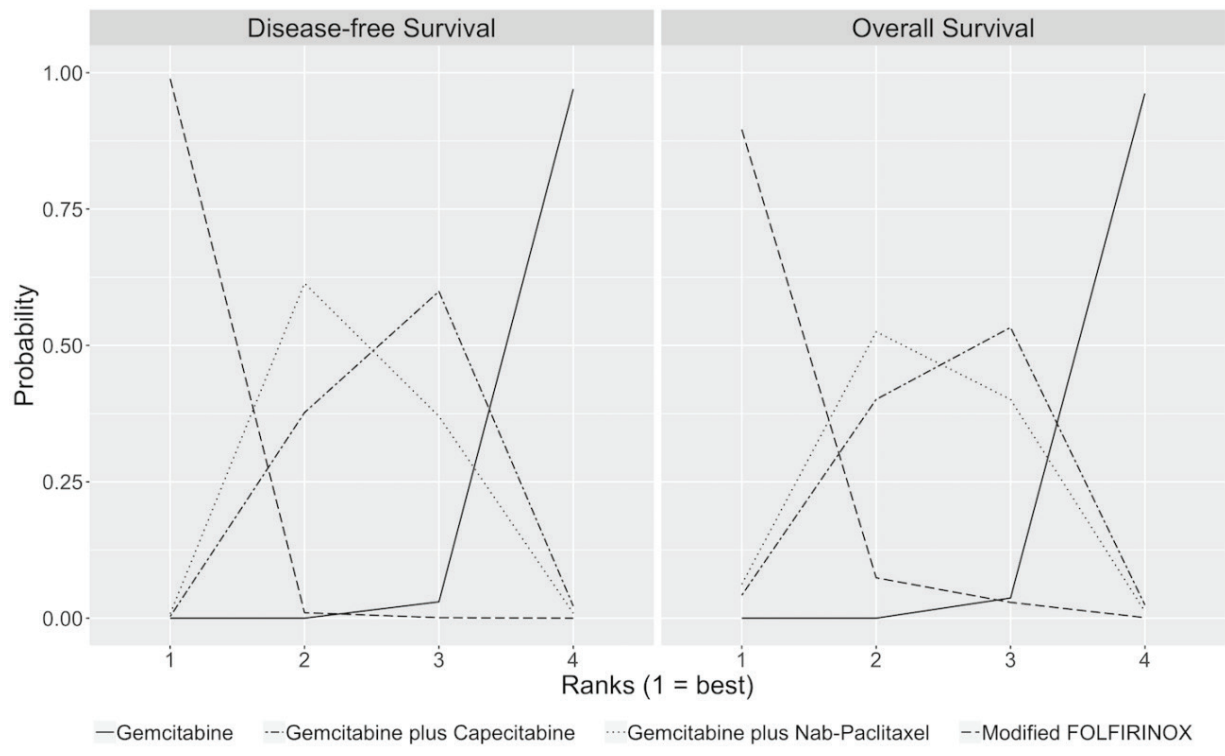

Figure 2. Rankograms for DFS and OS show the probability that each chemotherapy regimen has of being the first, second, third and fourth best chemotherapy regimen in terms of DFS and OS. These rankograms are created by assessing throughout the cycles from the MCMC the relative frequency in which the coefficient of the HR (log HR) for one specific chemotherapy regimen was greater or lesser than those of the other chemotherapy regimens. 
Toxicity

Table 5 describes the toxicity patterns observed in the three studies. In all studies, combination chemotherapy was associated with an increased risk of grade 3-4 toxicity. In ESPAC-4, GEM-CAP was associated with numerically increased rates of grade 3-4 neutropenia, diarrhoea and hand-foot syndrome. In PRODIGE 24, modified FOLFIRINOX was associated with increased rates of grade 3-4 fatigue, nausea, vomiting, diarrhoea and peripheral neuropathy. In the APACT trial, GEM-NAB was associated with higher frequency of grade 3-4 anaemia, fatigue, diarrhoea and peripheral neuropathy. By indirect comparison, patients treated with GEM-NAB experienced the highest rates of grade 3-4 anaemia, neutropenia and peripheral neuropathy. Patients who received modified FOLFIRINOX presented the highest frequency of grade 3-4 diarrhoea. GEM-CAP was the regimen which most commonly led to hand-foot syndrome. However, it is worth noting that when we evaluate only the single-agent gemcitabine arms of the trials, rates of grade 3-4 haematological toxicities were higher in the APACT when compared to the other studies. Thus, indirect comparisons of toxicities across trials should be interpreted with caution.

\section{Discussion}

In our study, modified FOLFIRINOX was the chemotherapy regimen most likely to represent the best currently available option in the adjuvant treatment of pancreatic ductal adenocarcinoma. While the PRODIGE 24 had a lower median follow-up compared to the other two studies and had a rather selected patient population in terms of age and post-operative CA 19-9 levels, modified FOLFIRINOX had 98.9\% and $89.6 \%$ chance of being the most active chemotherapy regimen in terms of investigator-assessed DFS and OS, respectively. These results are in line with the ones found in a previous Bayesian network meta-analysis including patients with more advanced disease [27]. That said, while long-term survival outcomes of this trial are expected, we believe that FOLFIRINOX is currently the standard of care for all the patients with resected pancreatic cancer who are fit enough to undergo adjuvant chemotherapy with this regimen.

However, some patients will not be optimal candidates to adjuvant treatment with modified FOLFIRINOX. Notably, among the highly selected patient population enrolled in the PRODIGE 24 trial, roughly one-third could not complete the planned 12 cycles of modified FOLFIRINOX; this rate is likely to be even higher among real-world patients. Also, 33\% of all patients diagnosed with localised pancreatic cancer in the USA are older than 80 years at diagnosis [29] and it is currently unknown whether this chemotherapy regimen is safe enough for patients in this age group as they were not included in the PRODIGE 24 trial. Moreover, patients with dihydropyrimidine dehydrogenase (DPD) deficiency (present in $8 \%$ of African-American and 3-5\% of Caucasian patients) [30] are at increased risk of toxicity when treated with fluoropyrimidines while those with uridine diphosphate glucoronosyltransferase 1 A (UGT1A) polymorphisms (present in at least $20 \%$ of Caucasians and $15 \%$ of African-Americans or Asian patients) [31] are at an increased risk of toxicity when treated with irinotecan. While adjustments in the dose of irinotecan seem to be sufficient to decrease the risk of severe toxicity even in patients with homozygous UGT1A polymorphism [32], treatment with a fluoropyrimidine in patients with severe DPD deficiency is associated with a prohibitively high risk of severe toxicity and is not recommended [33]. Additionally, other limitations associated with the use of FOLFIRINOX include the need for a permanent catheter and the cumulative cold-induced peripheral neuropathy (particularly relevant in regions with long winters).

Table 4. SUCRA for DFS and OS.

\begin{tabular}{|l|c|c|}
\hline \multicolumn{1}{|c|}{ Chemotherapy } & DFS & OS \\
\hline Modified FOLFIRINOX & 0.996 & 0.955 \\
\hline GEM-NAB & 0.540 & 0.546 \\
\hline GEM-CAP & 0.454 & 0.487 \\
\hline Gemcitabine & 0.010 & 0.013 \\
\hline
\end{tabular}


Table 5. Toxicity patterns of studies' treatments.

\begin{tabular}{|c|c|c|c|c|c|c|}
\hline & \multicolumn{2}{|c|}{ ESPAC-4 } & \multicolumn{2}{|c|}{ PRODIGE 24} & \multicolumn{2}{|c|}{ APACT } \\
\hline & Gemcitabine & GEM-CAP & Gemcitabine & $\begin{array}{l}\text { Modified FOL- } \\
\text { FIRINOX }\end{array}$ & Gemcitabine & GEM-NAB \\
\hline & $N=366(\%)$ & $N=359(\%)$ & $N=243(\%)$ & $N=238(\%)$ & $N=423(\%)$ & $N=429(\%)$ \\
\hline All Grade 3-4 & $196(53.6)$ & $226(63.0)$ & $128(52.9)$ & 180 (75.9) & $286(67.6)$ & $371(86.5)$ \\
\hline \multicolumn{7}{|l|}{ Haematological } \\
\hline $\begin{array}{l}\text { Anaemia } \\
\text { All grades } \\
\text { Grades 3-4 } \\
\end{array}$ & $14(3.8)$ & $\begin{array}{c}- \\
8(2.2) \\
\end{array}$ & $\begin{array}{c}216(89.3) \\
6(2.5) \\
\end{array}$ & $\begin{array}{c}200(84.7) \\
8(3.4) \\
\end{array}$ & $33(7.8)$ & $63(14.7)$ \\
\hline $\begin{array}{l}\text { Neutropenia } \\
\text { All grades } \\
\text { Grades 3-4 }\end{array}$ & $89(24.3)$ & $137(38.2)$ & $\begin{array}{c}154(63.6) \\
63(26.0) \\
\end{array}$ & $\begin{array}{c}157(66.5) \\
67(28.4) \\
\end{array}$ & $184(43.5)$ & $212^{-}(49.4)$ \\
\hline $\begin{array}{l}\text { Febrile neutropenia } \\
\text { Grade 3-4 }\end{array}$ & - & - & $10(4.1)$ & $7(3.0)$ & $21(5.0)$ & $4(0.9)$ \\
\hline $\begin{array}{l}\text { Thrombocytopenia } \\
\text { All grades } \\
\text { Grades 3-4 }\end{array}$ & $7(1.9)$ & $8(2.2)$ & $\begin{array}{c}122(50.4) \\
11(4.5) \\
\end{array}$ & $\begin{array}{c}111(47.0) \\
3(1.3) \\
\end{array}$ & - & $\begin{array}{l}- \\
- \\
\end{array}$ \\
\hline $\begin{array}{l}\text { Lymphopenia } \\
\text { All grades } \\
\text { Grades 3-4 }\end{array}$ & $11(3.0)$ & $9(2.5)$ & $\begin{array}{c}117(48.3) \\
7(2.9)\end{array}$ & $\begin{array}{c}87(36.9) \\
3(1.3)\end{array}$ & $\begin{array}{l}- \\
-\end{array}$ & - \\
\hline \multicolumn{7}{|l|}{ Non-haematological } \\
\hline $\begin{array}{l}\text { Fatigue } \\
\text { All grades } \\
\text { Grades 3-4 }\end{array}$ & $19(5.2)$ & $20(5.6)$ & $\begin{array}{c}187(77.6) \\
11(4.6) \\
\end{array}$ & $\begin{array}{c}199(84.0) \\
26(11.0) \\
\end{array}$ & $13(3.1)$ & $43(10)$ \\
\hline $\begin{array}{l}\text { Nausea } \\
\text { All grades } \\
\text { Grades 3-4 }\end{array}$ & - & - & $\begin{array}{c}133(5.2) \\
2(0.8)\end{array}$ & $\begin{array}{c}187(78.9) \\
13(5.5)\end{array}$ & - & $\begin{array}{l}- \\
-\end{array}$ \\
\hline $\begin{array}{l}\text { Vomiting } \\
\text { All grades } \\
\text { Grades 3-4 } \\
\end{array}$ & - & - & $\begin{array}{c}70(29.0) \\
3(1.2) \\
\end{array}$ & $\begin{array}{c}108(45.6) \\
12(5.1) \\
\end{array}$ & - & - \\
\hline $\begin{array}{l}\text { Diarrhoea } \\
\text { All grades } \\
\text { Grades 3-4 }\end{array}$ & $6(1.6)$ & $19 \stackrel{-}{(5.3)}$ & $\begin{array}{c}118(49.0) \\
9(3.7)\end{array}$ & $\begin{array}{c}200(84.4) \\
44(18.6)\end{array}$ & $4(0.9)$ & $22(5.1)$ \\
\hline $\begin{array}{l}\text { Mucositis } \\
\text { All grades } \\
\text { Grades 3-4 }\end{array}$ & - & $\begin{array}{l}- \\
-\end{array}$ & $\begin{array}{c}36(14.9) \\
0(0.0)\end{array}$ & $\begin{array}{c}80(33.8) \\
6(2.5)\end{array}$ & - & $\begin{array}{l}- \\
-\end{array}$ \\
\hline $\begin{array}{l}\text { Hand-foot syndrome } \\
\text { All grades } \\
\text { Grades 3-4 }\end{array}$ & $0(0.0)$ & $\begin{array}{c}- \\
26(7.2)\end{array}$ & $\begin{array}{c}2(0.8) \\
0(0)\end{array}$ & $\begin{array}{c}12(5.1) \\
1(0.4)\end{array}$ & $\begin{array}{l}- \\
-\end{array}$ & $\begin{array}{l}- \\
-\end{array}$ \\
\hline $\begin{array}{l}\text { Peripheral neuropathy } \\
\text { All grades } \\
\text { Grades 3-4 }\end{array}$ & $\begin{array}{l}- \\
-\end{array}$ & - & $\begin{array}{c}21(8.7) \\
0(0.0)\end{array}$ & $\begin{array}{c}145(61.2) \\
22(9.3)\end{array}$ & $0(0.0)$ & $64(14.9)$ \\
\hline $\begin{array}{l}\text { Alopecia } \\
\text { All grades }\end{array}$ & - & - & $47(19.5)$ & $64(27.0)$ & - & - \\
\hline $\begin{array}{l}\text { Thrombosis } \\
\text { All grades } \\
\text { Grades 3-4 }\end{array}$ & $9(2.5)$ & $8(2.2)$ & $\begin{array}{l}19(79) \\
1(0.4)\end{array}$ & $\begin{array}{c}14(5.9) \\
6(2.5)\end{array}$ & $\begin{array}{l}- \\
-\end{array}$ & $\begin{array}{l}- \\
-\end{array}$ \\
\hline
\end{tabular}


Apart from toxicity concerns, recent data points out that the efficacy of 5-Fluorouracil-based chemotherapy in pancreatic cancer might depend on the patterns of tumour gene expression. GATA6 is a transcription factor associated with cell differentiation in early pancreatic embryogenesis and low levels of GATA6 are associated with basal-like (or quasi-mesenchymal) gene expression profile. While no prospective randomised trial in the adjuvant setting has been specifically designed to assess this hypothesis, a retrospective analysis from the ESPAC-3 trial showed that patients who had tumours with low or medium levels of GATA6 expression who were treated with 5-Fluorouracil had worse survival when compared to those with high-level tumours [34]. The same phenomenon was not seen for those treated with gemcitabine. Also, pre-clinical data have shown that gemcitabine treatment might be more active against tumours with basal-like (or quasi-mesenchymal) gene expression profile (and therefore, low levels of GATA6 expression) [35] and recent data in the metastatic setting support the effects of this treatment interaction [36]. Thus, while GATA6 expression and gene expression profiling are not currently used to tailor adjuvant chemotherapy for pancreatic cancer, compelling emerging data suggest the choice of fluoropyrimidine-based or gemcitabine-based chemotherapy could be guided by the molecular characteristics of the tumour.

The use of gemcitabine-based doublets could match the need for less toxic or non-fluoropyrimidine-based regimens in the adjuvant setting. In this sense, we showed that GEM-NAB is likely associated with the highest probability of being the best gemcitabine-based treatment in terms of both investigator-assessed DFS and OS. GEM-CAP had a slightly worse performance than GEM-NAB in terms of survival outcomes. Also, in the real world, the use of GEM-CAP has been shown to be challenging given its toxicity profile [37]. Likewise, the rate of chemotherapy completion among patients treated with GEM-CAP in the ESPAC-4 study was the lowest among the three studies - Supplementary Table 2. Furthermore, retrospective data from the X-ACT study in colon cancer suggest worse tolerance to fluoropyrimidine among North Americans when compared to Europeans [38]. Because only European patients were included in the ESPAC-4, non-European Western patients might face even more difficulties in trying to complete adjuvant chemotherapy with GEM-CAP. However, despite potential differences in the chances of experiencing chemotherapy-related toxicity between North Americans and Europeans, it is important to state that current data support similar survival rates for patients with stage I-II pancreatic cancer who undergo resection in the United States and in Europe [39], which suggest that potential differences in survival outcomes across these trials are probably not secondary to ethnic or geographical reasons.

Despite these results, one might say that GEM-NAB should not be considered a treatment option in this setting since the APACT trials failed to meet the primary endpoint of DFS as assessed by the independent review. We believe that the conclusion as to whether a trial is considered positive or negative is complex and should not rely solely on the statistical significance of the test for the primary outcome [40]. The APACT investigators chose the independently reviewed DFS as the primary outcome in an attempt to improve reproducibility. Nonetheless, pancreatic cancer relapse is often suspected based on clinical (symptoms) or laboratory (CA 19-9 levels) information, which is not available for the independent reviewers [41, 42]. These data seem particularly important for patients with locoregional recurrences, which might be very difficult to distinguish from post-operative alterations based only on radiological grounds [43, 44]. Accordingly, a recent analysis from the APACT trial showed that there were significant discordances in the number of DFS events between independent and investigator assessment that likely influenced outcomes [21].

Another argument that supports the use of GEM-NAB in the adjuvant setting is the significant OS benefit. This outcome is perceived by many experts in pancreatic cancer as the most important indicator of outcome quality [45]. Accordingly, OS was the primary outcome for both the PRODIGE 24 and the ESPAC-4 trials. Interestingly, in the latter study, the OS benefits were considered significant despite the lack of significant improvement in DFS. Additionally, in the recently presented SWOG S1505 trial [46], which compared perioperative modified FOLFIFIRINOX to perioperative GEM-NAB in the resectable disease setting, no significant differences in DFS and OS times were found. That said, despite the limited sample size and some methodological issues, the results of SWOG S1505 suggest that FOLFIRINOX and GEM-NAB offer similar anti-tumour activity in localised pancreatic cancer, further supporting the use of adjuvant GEM-NAB in case modified FOLFIRINOX is not feasible.

Patients treated with single-agent gemcitabine in the ESPAC-4 trial experienced numerically worse OS when compared to those in the PRODIGE24 and APACT trials. That is in line with the distribution of known prognostic factors, such as ECOG and stage, across these studies. This might have favoured the modified FOLFIRINOX and GEM-NAB arms when compared to GEM-CAP, at least in terms of absolute survival benefit. Furthermore, the lack of seemly significant differences in median relapse-free survival across the single-agent gemcitabine 
arms in these trials suggests that factors apart from the adjuvant chemotherapy regimen might have played a part in determining OS, such as characteristics of the post-progression therapy.

Our study has limitations. We did not carry out a systematic search for all the articles comparing different adjuvant chemotherapy regimens for patients with resected pancreatic cancer. Nevertheless, apart from S-1 which is used almost exclusively in Asia, it is largely known by those with expertise in pancreatic cancer that these are the most clinically relevant chemotherapy regimens tested in randomised trials in the adjuvant setting. Furthermore, inconsistencies in the descriptions of the toxicities prevented us from making indirect comparisons of grade 3-4 or severe adverse events. However, we displayed the data from the studies in a way that readers can have an idea of the comparative risks of toxicities. Our study also has merits. As far as we know, this is the first Bayesian network meta-analysis evaluating the comparative effectiveness of these chemotherapy regimens. With this methodology, we were able to rank the efficacy of these regimens using a probabilistic approach that can aid the decision-making process. Moreover, we used matched outcomes, considering differences in independent reviewer-assessed and investigator-assessed DFSs. Furthermore, we present updated results for survival analysis from two of the three studies.

\section{Conclusion}

Modified FOLFIRINOX is the standard of care for the treatment of pancreatic cancer in the adjuvant setting for patients fit enough to receive this chemotherapy regimen. For those with contraindications or who are not fit enough for modified FOLFIRINOX, GEM-NAB might be the preferred adjuvant therapy, particularly to those patients who have contraindications for fluoropyrimidines.

\section{Conflicts of interest}

Victor Hugo Fonseca de Jesus received honoraria from United Medical and had travel expenses paid by United Medical in the past 12 months. United Medical is the company responsible for the distribution and sale of nab-paclitaxel in Brazil. Rachel Pimenta Riechelmann received consultancy fees from Astra Zeneca in the past 12 months.

\section{Funding source}

This study had no funding source.

\section{Authors' contributions}

Victor Hugo Fonseca de Jesus: conceptualisation, methodology, data curation, data analyses, writing and visualisation; Rachel Pimenta Riechelmann: methodology, writing and visualisation.

\section{Acknowledgment}

The authors would like to thank Vinicius Fernando Calsavara (chief statistician) for reviewing the WinGUBS codes for the Bayesian network meta-analysis. 


\section{References}

1. Bray F, Ferlay J, and Soerjomataram I, et al (2018) Global cancer statistics 2018: GLOBOCAN estimates of incidence and mortality worldwide for 36 cancers in 185 countries CA Cancer J Clin 68(6) 394-424 https://doi.org/10.3322/caac.21492 PMID: 30207593

2. Quante AS, Ming C, and Rottmann M, et al (2016) Projections of cancer incidence and cancer-related deaths in Germany by 2020 and 2030 Cancer Med 5(9) 2649-2656 https://doi.org/10.1002/cam4.767 PMID: 27356493 PMCID: 5055190

3. Rahib L, Smith BD, and Aizenberg R, et al (2014) Projecting cancer incidence and deaths to 2030: the unexpected burden of thyroid, liver, and pancreas cancers in the United States Cancer Res 74(11) 2913-2921 https://doi.org/10.1158/0008-5472.CAN-14-0155 PMID: 24840647

4. Barbosa IR, Santos CAd, and Souza DLBd (2018) Pancreatic cancer in Brazil: mortality trends and projections until 2029 Arq Gastroenterol 55 230-236 https://doi.org/10.1590/s0004-2803.201800000-59 PMID: 30540083

5. Mizrahi JD, Surana R, and Valle JW, et al (2020) Pancreatic cancer The Lancet 395(10242) 2008-2020 https://doi.org/10.1016/S01406736(20)30974-0

6. Longmire WP, Jr. and Traverso LW (1981) The Whipple procedure and other standard operative approaches to pancreatic cancer Cancer 47(6 Suppl) 1706-1711 https://doi.org/10.1002/1097-0142(19810315)47:6+<1706::AID-CNCR2820471441>3.0.CO;2-7 PMID: 6791804

7. Neoptolemos JP, Stocken DD, and Friess $\mathrm{H}$, et al (2004) A randomized trial of chemoradiotherapy and chemotherapy after resection of pancreatic cancer N Engl J Med 350(12) 1200-1210 https://doi.org/10.1056/NEJMoa032295 PMID: 15028824

8. Oettle H, Neuhaus $P$, and Hochhaus $A$, et al (2013) Adjuvant chemotherapy with gemcitabine and long-term outcomes among patients with resected pancreatic cancer: the CONKO-001 randomized trial JAMA 310(14) 1473-1481 https://doi.org/10.1001/ jama.2013.279201 PMID: 24104372

9. Oettle H, Post S, and Neuhaus P, et al (2007) Adjuvant chemotherapy with gemcitabine vs observation in patients undergoing curativeintent resection of pancreatic cancer: a randomized controlled trial JAMA 297(3) 267-277 https://doi.org/10.1001/jama.297.3.267 PMID: 17227978

10. Neoptolemos JP, Stocken DD, and Bassi C, et al (2010) Adjuvant chemotherapy with fluorouracil plus folinic acid vs gemcitabine following pancreatic cancer resection: a randomized controlled trial JAMA 304(10) 1073-1081 https://doi.org/10.1001/jama.2010.1275 PMID: 20823433

11. Conroy T, Desseigne F, and Ychou M, et al (2011) FOLFIRINOX versus gemcitabine for metastatic pancreatic cancer N Engl J Med 364(19) 1817-1825 https://doi.org/10.1056/NEJMoa1011923 PMID: 21561347

12. Von Hoff DD, Ervin T, and Arena FP, et al (2013) Increased survival in pancreatic cancer with nab-paclitaxel plus gemcitabine $N$ Engl J Med 369(18) 1691-1703 https://doi.org/10.1056/NEJMoa1304369 PMID: 24131140 PMCID: 4631139

13. Sultana A, Smith CT, and Cunningham D, et al (2007) Meta-analyses of chemotherapy for locally advanced and metastatic pancreatic cancer J Clin Oncol 25(18) 2607-2615 https://doi.org/10.1200/JCO.2006.09.2551 PMID: 17577041

14. Sinn M, Bahra M, and Liersch T, et al (2017) CONKO-005: adjuvant chemotherapy with gemcitabine plus erlotinib versus gemcitabine alone in patients after RO resection of pancreatic cancer: a multicenter randomized phase III trial J Clin Oncol 35(29) 3330-3337 https://doi.org/10.1200/JCO.2017.72.6463 PMID: $\underline{28817370}$

15. Safran H, Winter KA, and Abrams RA, et al (2017) Results of the randomized phase II portion of NRG Oncology/RTOG 0848 evaluating the addition of erlotinib to adjuvant gemcitabine for patients with resected pancreatic head adenocarcinoma J Clin Oncol35(15_suppl) 4007 https://doi.org/10.1200/JCO.2017.35.15_suppl.4007 
16. Neoptolemos JP, Palmer DH, and Ghaneh P, et al (2017) Comparison of adjuvant gemcitabine and capecitabine with gemcitabine monotherapy in patients with resected pancreatic cancer (ESPAC-4): a multicentre, open-label, randomised, phase 3 trial Lancet 389(10073) 1011-1024 https://doi.org/10.1016/S0140-6736(16)32409-6 PMID: 28129987

17. Conroy T, Hammel P, and Hebbar M, et al (2018) FOLFIRINOX or gemcitabine as adjuvant therapy for pancreatic cancer N Engl J Med 379(25) 2395-2406 https://doi.org/10.1056/NEJMoa1809775 PMID: 30575490

18. Tempero MA, Reni M, and Riess H, et al (2019) APACT: phase III, multicenter, international, open-label, randomized trial of adjuvant nab-paclitaxel plus gemcitabine (nab-P/G) vs gemcitabine (G) for surgically resected pancreatic adenocarcinoma J Clin Oncol 37(15_ suppl) 4000 https://doi.org/10.1200/JCO.2019.37.15_suppl.4000

19. Jansen JP, Crawford B, and Bergman G, et al (2008) Bayesian meta-analysis of multiple treatment comparisons: an introduction to mixed treatment comparisons Value Health 11(5) 956-964 https://doi.org/10.1111/j.1524-4733.2008.00347.x PMID: 18489499

20. Neoptolemos JP, Palmer DH, and Ghaneh P, et al (2020) ESPAC-4: a multicenter, international, open-label randomized controlled phase III trial of adjuvant combination chemotherapy of gemcitabine (GEM) and capecitabine (CAP) versus monotherapy gemcitabine in patients with resected pancreatic ductal adenocarcinoma: five year follow-up J Clin Oncol 38(15_suppl) 4516 https://doi.org/10.1200/ JCO.2020.38.15_suppl.4516

21. Reni M, Riess H, and O'Reilly EM, et al (2020) Concordance between independent and investigator assessment of disease-free survival (DFS) in the APACT trial J Clin Oncol 38(15_suppl) 4618 https://doi.org/10.1200/JCO.2020.38.15_suppl.4618

22. Harrer M, Cuijpers P, and Furukawa TA, et al (2019) Doing Meta-Analysis in R: A Hands-on Guide https://bookdown.org/MathiasHarrer/ Doing_Meta_Analysis_in_R/bayesian-ma.html

23. Parmar MKB, Torri $V$, and Stewart $L(1998)$ Extracting summary statistics to perform meta-analyses of the published literature for survival endpoints Stat Med 17(24) 2815-2834 https://doi.org/10.1002/(SICI)1097-0258(19981230)17:24<2815::AID-SIM110>3.0.CO;2-8

24. Hu D, O'Connor AM, and Wang C, et al (2020) How to conduct a Bayesian network meta-analysis Front Vet Sci 7271 https://doi. org/10.3389/fvets.2020.00271 PMID: 32509807 PMCID: 7248597

25. Karner C, Kew K, and Wakefield V, et al (2019) Targeted therapies for previously treated advanced or metastatic renal cell carcinoma: systematic review and network meta-analysis BMJ Open 9(3) e024691 https://doi.org/10.1136/bmjopen-2018-024691 PMID: 30826762 PMCID: 6429896

26. Brooks SP and Gelman A (1998) General methods for monitoring convergence of iterative simulations J Comput Graphical Stat 7(4) 434-455

27. Gresham GK, Wells GA, and Gill S, et al (2014) Chemotherapy regimens for advanced pancreatic cancer: a systematic review and network meta-analysis BMC Cancer 14(1) https://doi.org/10.1186/1471-2407-14-471 PMID: 24972449 PMCID: 4097092

28. Salanti G, Ades AE, and loannidis JP (2011) Graphical methods and numerical summaries for presenting results from multiple-treatment meta-analysis: an overview and tutorial J Clin Epidemiol 64(2) 163-171 https://doi.org/10.1016/j.jclinepi.2010.03.016

29. Wang H, Liu J, and Xia G, et al (2020) Survival of pancreatic cancer patients is negatively correlated with age at diagnosis: a populationbased retrospective study Sci Rep 10(1) 7048 https://doi.org/10.1038/s41598-020-64068-3 PMID: 32341400 PMCID: 7184604

30. Mattison LK, Fourie J, and Desmond RA, et al (2006) Increased prevalence of dihydropyrimidine dehydrogenase deficiency in AfricanAmericans compared with Caucasians Clin Cancer Res 12(18) 5491-5495 https://doi.org/10.1158/1078-0432.CCR-06-0747 PMID: 17000684

31. Takano M and Sugiyama T (2017) UGT1A1 polymorphisms in cancer: impact on irinotecan treatment Pharmacogenomics Pers Med 10 61-68 
32. Shirasu H, Todaka A, and Omae K, et al (2019) Impact of UGT1A1 genetic polymorphism on toxicity in unresectable pancreatic cancer patients undergoing FOLFIRINOX Cancer Sci 110(2) 707-716 https://doi.org/10.1111/cas.13883 PMCID: 6361560

33. Lunenburg C, van der Wouden CH, and Nijenhuis M, et al (2020) Dutch Pharmacogenetics Working Group (DPWG) guideline for the gene-drug interaction of DPYD and fluoropyrimidines Eur J Human Genet 28(4) 508-517 https://doi.org/10.1038/s41431-019-0540-0

34. Martinelli P, Carrillo-de Santa Pau E, and Cox T, et al (2017) GATA6 regulates EMT and tumour dissemination, and is a marker of response to adjuvant chemotherapy in pancreatic cancer Gut 66(9) 1665-1676 https://doi.org/10.1136/gutjnl-2015-311256

35. Collisson EA, Sadanandam A, and Olson P, et al (2011) Subtypes of pancreatic ductal adenocarcinoma and their differing responses to therapy Nat Med 17(4) 500-503 https://doi.org/10.1038/nm.2344 PMID: 21460848 PMCID: 3755490

36. O'Kane GM, Fischer S, and Denroche R, et al (2019) Integrative molecular profiling and response to chemotherapy on the COMPASS trial J Clin Oncol 37(4_suppl) 188 https://doi.org/10.1200/JCO.2019.37.4_suppl.188

37. Kaur G, Jahangiri V, and Park SJ, et al (2019) Efficacy and tolerability of adjuvant gemcitabine and capecitabine in patients with resected pancreatic cancer in US population: a single network experience J Clin Oncol 37(15_suppl) e15789 https://doi.org/10.1200/ JCO.2019.37.15_suppl.e15789

38. Haller DG, Cassidy J, and Clarke SJ, et al (2008) Potential regional differences for the tolerability profiles of fluoropyrimidines J Clin Oncol 26(13) 2118-2123 https://doi.org/10.1200/JCO.2007.15.2090 PMID: 18445840

39. Huang L, Jansen L, and Balavarca Y, et al (2018) Stratified survival of resected and overall pancreatic cancer patients in Europe and the USA in the early twenty-first century: a large, international population-based study BMC Med 16(1) 125 https://doi.org/10.1186/ s12916-018-1120-9 PMID: 30126408 PMCID: 6102804

40. Pocock SJ and Stone GW (2016) The primary outcome fails - what next? N Engl J Med 375(9) 861-870 https://doi.org/10.1056/ NEJMra1510064 PMID: 27579636

41. Nordby T, Hugenschmidt $\mathrm{H}$, and Fagerland MW, et al (2013) Follow-up after curative surgery for pancreatic ductal adenocarcinoma: asymptomatic recurrence is associated with improved survival Eur J Surg Oncol 39(6) 559-566 https://doi.org/10.1016/j. ejso.2013.02.020 PMID: 23498362

42. Groot VP, Daamen LA, and Hagendoorn J, et al (2018) Use of imaging during symptomatic follow-up after resection of pancreatic ductal adenocarcinoma J Surg Res 221 152-160 https://doi.org/10.1016/j.jss.2017.08.023

43. Aleotti F, Crippa S, and Sebastiani E, et al (2015) Is surgery an option after down staging of liver metastases from pancreatic cancer following primary chemotherapy? Pancreatology 15(3) S89

44. Ishigami K, Yoshimitsu K, and Irie H, et al (2008) Significance of perivascular soft tissue around the common hepatic and proximal superior mesenteric arteries arising after pancreaticoduodenectomy: evaluation with serial MDCT studies Abdom Imaging 33(6) 654-661 https://doi.org/10.1007/s00261-008-9359-9 PMID: 18219520

45. Strobel O, Neoptolemos J, and Jäger D, et al (2019) Optimizing the outcomes of pancreatic cancer surgery Nat Rev Clin Oncol 16(1) 11-26 https://doi.org/10.1038/s41571-018-0112-1

46. Sohal D, Duong MT, and Ahmad SA, et al (2020) SWOG S1505: Results of perioperative chemotherapy (peri-op CTx) with mfolfirinox versus gemcitabine/nab-paclitaxel (Gem/nabP) for resectable pancreatic ductal adenocarcinoma (PDA) J Clin Oncol 38(15_suppl) 4504 https://doi.org/10.1200/JCO.2020.38.15_suppl.4504 


\section{Supplementary material}

\section{Supplementary tables}

Supplementary Table 1. Inclusion and exclusion criteria.

\begin{tabular}{|c|c|c|c|}
\hline & ESPAC-4 & PRODIGE 24 & APACT \\
\hline \multicolumn{4}{|l|}{ Inclusion } \\
\hline Age (years) & $\geq 18$ & $18-79$ & $\geq 18$ \\
\hline Histology & Ductal adenocarcinoma & Ductal adenocarcinoma & Ductal adenocarcinoma \\
\hline Extent of resection & $\mathrm{R} 0^{\mathrm{a}}$ or $\mathrm{R} 1$ & $\mathrm{RO}^{\mathrm{a}}$ or $\mathrm{R} 1$ & $\mathrm{R} 0$ or $\mathrm{R} 1$ \\
\hline Time from surgery (weeks) & - & $3-12$ & $<12$ \\
\hline Staging & Non-metastatic & Non-metastatic ${ }^{b}$ & I or II \\
\hline Performance status (ECOG) & $0-2$ & 0 and 1 & 0 and 1 \\
\hline Organ function & $\begin{array}{l}\text { Adequate haematologic, } \\
\text { renal and hepatic functions }\end{array}$ & $\begin{array}{l}\text { Adequate haematologic, } \\
\text { renal and hepatic functions }\end{array}$ & - \\
\hline \multicolumn{4}{|l|}{ Exclusion } \\
\hline Post-operative tumor marker (U/mL) & No restriction & $>180$ & $>100$ \\
\hline Previous treatment & $\begin{array}{l}\text { Radiotherapy or } \\
\text { chemotherapy }\end{array}$ & $\begin{array}{l}\text { Radiotherapy or } \\
\text { chemotherapy }\end{array}$ & $\begin{array}{l}\text { Radiotherapy or } \\
\text { chemotherapy }\end{array}$ \\
\hline Comorbidity & - & $\begin{array}{l}\text { Symptomatic coronary } \\
\text { artery disease or } \\
\text { congestive heart failure }\end{array}$ & - \\
\hline
\end{tabular}

aDefined as no cancer cells within $1 \mathrm{~mm}$ of all resection margins

${ }^{\mathrm{b}} \mathrm{Clear} \mathrm{CT}$ scan of chest, abdomen, and pelvis required within 3 months before randomization

${ }^{\mathrm{C}} \mathrm{CT}$ without evidence of disease

Supplementary Table 2. Treatment compliance.

\begin{tabular}{|c|c|c|c|c|c|c|}
\hline & \multicolumn{2}{|c|}{ ESPAC-4 } & \multicolumn{2}{|c|}{ PRODIGE 24} & \multicolumn{2}{|c|}{ APACT } \\
\hline & Gemcitabine & $\begin{array}{l}\text { Gemcitabine plus } \\
\text { Capecitabine }\end{array}$ & Gemcitabine & $\begin{array}{c}\text { Modified } \\
\text { FOLFIRINOX }\end{array}$ & Gemcitabine & $\begin{array}{c}\text { Gemcitabine plus } \\
\text { Nab-Paclitaxel }\end{array}$ \\
\hline & $N=366$ & $N=364$ & $N=246$ & $N=247$ & $N=423$ & $N=429$ \\
\hline $\begin{array}{l}\text { Dose intensity - \% } \\
\text { Gemcitabine } \\
\text { Capecitabine } \\
\text { 5-Fluorouracil } \\
\text { Oxaliplatin } \\
\text { Irinotecan } \\
\text { Nab-Paclitaxel }\end{array}$ & $\begin{array}{c}93.0 \\
- \\
- \\
- \\
- \\
-\end{array}$ & $\begin{array}{c}83.0 \\
78.0 \\
- \\
- \\
- \\
-\end{array}$ & $\begin{array}{l}- \\
- \\
- \\
- \\
- \\
-\end{array}$ & $\begin{array}{l}- \\
- \\
- \\
- \\
- \\
-\end{array}$ & $\begin{array}{c}91.2 \\
- \\
- \\
- \\
- \\
-\end{array}$ & $\begin{array}{c}80.0 \\
- \\
- \\
- \\
- \\
75.1\end{array}$ \\
\hline $\begin{array}{l}\text { Treatment } \\
\text { completion (\%) } \\
\text { Yes } \\
\text { No }\end{array}$ & $\begin{array}{l}239(65.3) \\
127(34.7)\end{array}$ & $\begin{array}{l}195(53.6) \\
169(46.4)\end{array}$ & $\begin{array}{l}192(79.0) \\
54(21.0)\end{array}$ & $\begin{array}{c}158(66.4) \\
89(33.6)\end{array}$ & $\begin{array}{l}300(70.9) \\
123(29.1)\end{array}$ & $\begin{array}{c}283(66.0)^{a} \\
146(34.0)\end{array}$ \\
\hline
\end{tabular}

an cycle $6,59 \%$ of patients on Gemcitabine plus Nab-Paclitaxel received Nab-Paclitaxel 


\section{Codes for the WinBUGS}

\section{\# MODEL for OS}

\# Defining the model for log-hazard ratios (lhr)

model

\{

for(i in 1:ndp)\{

$\operatorname{prec}[\mathrm{i}]<-1 /\left(\operatorname{se}[\mathrm{i}]^{*} \mathrm{se}[\mathrm{i}]\right)$

$\operatorname{lhr}[\mathrm{i}] \sim \operatorname{dnorm}(\mathrm{md}[\mathrm{i}], \operatorname{prec}[\mathrm{i}])$

\# Defining the fixed-effect model for the log hazard ratios (lhr)

$m d[i]<-d[t[i]]-d[b[i]]$

\# Give priors to log hazard ratios (lhr)

$\mathrm{d}[1]<-0$

for ( $k$ in $2: n t)\{$

$\mathrm{d}[\mathrm{k}] \sim \operatorname{dnorm}(0, .001)$

\}

\# Defining ranks (rk)

for(k in 1:nt)

$\mathrm{rk}[\mathrm{k}]<-\operatorname{rank}(\mathrm{d}[\mathrm{k}, \mathrm{k})$

best $[k]<-$ equals $(r k[k], 1)$

\section{\# Defining SUCRA}

for(j in 1:nt)\{effectiveness[k,j]<-equals(rk[k],j)\}\}

for(k in 1:nt)\{for(j in 1:nt)\{cumeffectiveness[k,j]<-sum(effectiveness[k,1:j])\}\}

for(k in 1:nt)\{SUCRA[k]<-sum(cumeffectiveness[k,1:(nt-1)])/(nt-1)

\} 
\# Construct all pairwise log hazard ratios (Ihr) and hazard ratios (HR)

for (c in 1:nt-1)\{

for $(k$ in $(c+1): n t)\{$

$\operatorname{lhzr}[c, k]<-d[k]-d[c]$

$\mathrm{HR}[\mathrm{c}, \mathrm{k}]<-\exp (\mathrm{lhzr}[\mathrm{c}, \mathrm{k}])$

\}

\}

\}

\# Entering the data in the model (observed data)

data

\#\#\#\#\#\#\#\#

list $(n d p=3, n t=4, t=c(2,3,4), b=c(1,1,1), \operatorname{lhr}=c(-0.174353387,-0.198450939,-0.446287103), s e=c(0.088424645,0.088788212,0.14876180$ 7))

\#\#\#\#\#\#\#\#

\# Entering initial values in the model

initials

\# three chains

$\operatorname{list}(d=c(N A,-0.5,-0.5,-0.5))$

list $(\mathrm{d}=\mathrm{c}(\mathrm{NA}, 0,0,0)$

$\operatorname{list}(d=c(N A, 0.5,0.5,0.5))$

\# MODEL FOR DFS

\# Defining the model for log-hazard (lhr)

model

\{

for(i in 1:ndp)\{

$\operatorname{prec}[i]<-1 /\left(\operatorname{se}[i]^{*}\right.$ se $\left.[i]\right)$

Ihr[i] dnorm(md[i],prec[i]) 
\# Defining the fixed-effect model for the log hazard ratios (lhr)

$m d[i]<-d[t[i]]-d[b[i]]$

\# Give priors to log hazard ratios (lhr)

$\mathrm{d}[1]<-0$

for ( $k$ in $2: n t)\{$

$\mathrm{d}[\mathrm{k}] \sim \operatorname{dnorm}(0, .001)$

\}

\# Defining ranks (rk)

for(k in 1:nt)\{

$\operatorname{rk}[\mathrm{k}]<-\operatorname{rank}(\mathrm{d}[], \mathrm{k})$

best $[k]<-$ equals $(r k[k], 1)$

\# Defining SUCRA

for(j in 1:nt)\{effectiveness[k,j]<-equals(rk[k],j)\}\}

for(k in 1:nt)\{for(j in 1:nt)\{cumeffectiveness[k,j]<-sum(effectiveness[k,1:j])\}\}

for(k in 1:nt)\{SUCRA[k]<-sum(cumeffectiveness[k,1:(nt-1)])/(nt-1)

\}

\# Construct all pairwise log hazard ratios (lhr) and hazard ratios (HR)

for (c in 1:nt-1)\{

for $(k$ in $(c+1): n t)\{$

Ihzr $[c, k]<-d[k]-d[c]$

$H R[c, k]<-\exp (\operatorname{lhzr}[c, k])$

\}

\}

\}

ecancer 2021, 15:1276; www.ecancer.org; DOI: https://doi.org/10.3332/ecancer.2021.1276 


\section{\# Entering the data in the model (observed data)}

data

\#\#\#\#\#\#\#\#

list(ndp=3, nt=4, $t=c(2,3,4), b=c(1,1,1), \operatorname{lhr}=c(-0.1625189,-0.1984509,-0.5447272), \operatorname{se}=c(0.08028335,0.08409595,0.11781073))$

\#\#\#\#\#\#\#\#

\section{\# Entering initial values in the model}

initials

\# three chains

$\operatorname{list}(d=c(N A,-0.5,-0.5,-0.5))$

list $(d=c(N A, 0,0,0)$

$\operatorname{list}(d=c(N A, 0.5,0.5,0.5))$

\section{Formulas}

The formula below specifies the Bayesian model:

$$
\mathrm{Ihr}_{\mathrm{i}} \sim \mathrm{N}\left(\theta_{\mathrm{i}}, \mathrm{V}_{\mathrm{i}}\right)
$$

where $\mathbf{I h r} r_{i}$ represents trial-specific log hazard ratio and $\mathbf{V}_{\mathbf{i}}$ represents the within-trial variance. It is worth noting that in WinBUGS variance needs to be recorded as precision (precision being the inverse of the variance). As stated in the Methods section, we employed a pragmatic approach in which we fit a fixed-effect model to the data. In this setting, any difference between the log hazard ratios is believed to be due to sampling error [1]. In other words:

$$
\mathrm{Ihr}_{\mathrm{i}}=\theta+\varepsilon_{\mathrm{i}}
$$

where the sampling error $\varepsilon_{\mathrm{i}}$ is normally distributed with mean 0 and variance equal to the within-trial variance. This fixed-effect model can be described as:

$$
\theta_{i}=d_{t i}-d_{b i}
$$

where $\mathbf{d}_{b i}$ are defined as basic parameters and $\mathbf{d}_{\mathrm{ti}}$ are defined as functional parameters. For the basic parameters, a non-informative prior with mean 0 and variance 1000 was chosen. Further information can be found on the paper by Hu et al [2]

\section{References}

1. Wang S, Hawkins H. Indrotuction. In: Biondi-Zoccai G, editor. Network Meta-Analysis: Evidence Synthesis with Mixed Treatment Comparison. First ed: Nova Science; 2014. p. 157-70.

2. Hu D, O'Connor AM, Wang C, Sargeant JM, Winder CB. How to Conduct a Bayesian Network Meta-Analysis. Front Vet Sci. $2020 ; 7: 271$. 